- LA-UR- 98-4258

Aporoved for public release; distifibution is unlimited.

Title:

IS THE CURRENT CYLINDER TEST DATA ADEQUATE AS A BASELINE FOR COMPARISON ẆITH STOCKPILE RETURNED MATERIALS?

Author(s):

Maria Rightley

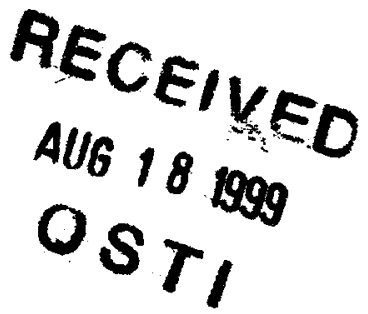

Submitted to:

Informal Report/Distribution upon request

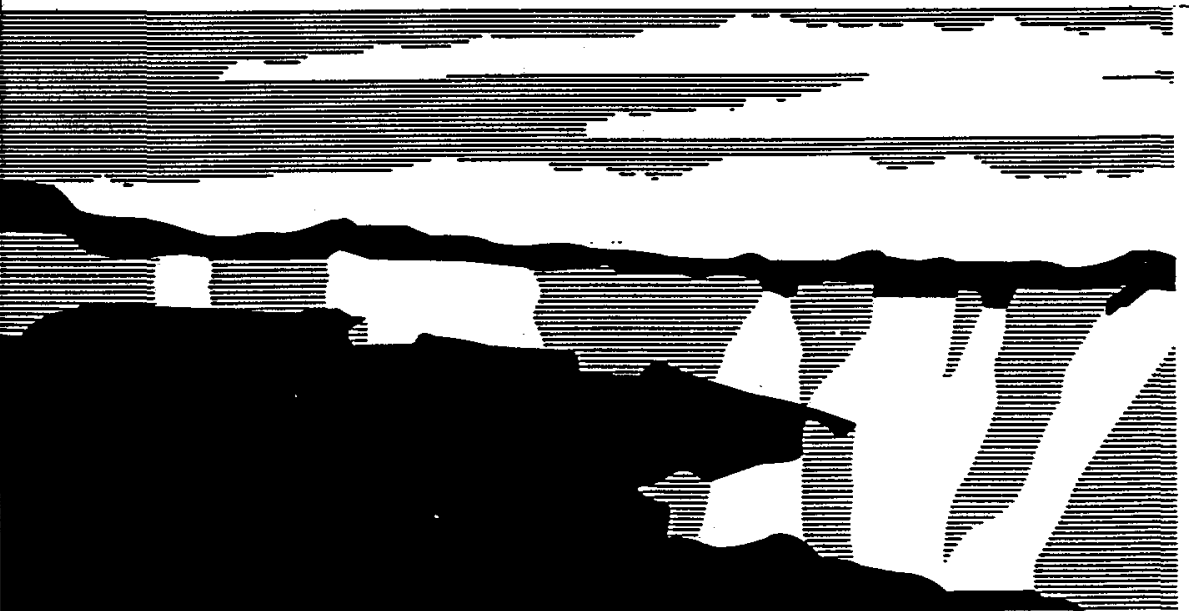

NATIONAL LABOAATORY

Los Alamos National Laboratory, an affimative actionequal opportunity employer, is operated by the University of Califoria for the U.S. Department of Energy under contract W-7405-ENG-36. By acceptance of this article, the publisher recognizes that the U.S. Govemment retains a nonexcluslve, royalty-free license to publish or reproduce the published form of this contribution, or to alliow others to do so, for U.S. Government purposes. Los Alamos National Laboratory requests that the publisher Identify this article as work performed under the ausplces of the U.S. Department of Energy. The Los Alamos National Laboratory strongly supports academic freedom and a reseancher's right to publish; as an institution, however, the Laboratory does not endorse the viewpoint of a publication or guarantee its technical comectness. 


\section{DISCLAIMER}

This report was prepared as an account of work sponsored by an agency of the United States Government. Neither the United States Government nor any agency thereof, nor any of their employees, make any warranty, express or implied, or assumes any legal liability or responsibility for the accuracy, completeness, or usefulness of any information, apparatus, product, or process disclosed, or represents that its use would not infringe privately owned rights. Reference herein to any specific commercial product, process, or service by trade name, trademark, manufacturer, or otherwise does not necessarily constitute or imply its endorsement, recommendation, or favoring by the United States Government or any agency thereof. The views and opinions of authors expressed herein do not necessarily state or reflect those of the United States Government or any agency thereof. 


\section{DISCLAIMER}

Portions of this document may be illegible in electronic image products. Images are produced from the best available original document. 


\title{
Is the Current Cylinder Test Data Adequate as a BASEline For COMPARison With STOCKPILE RETURNed MATERIAL?
}

\author{
Maria L. J. Rightley \\ $X N H, M S F 664$ \\ Los Alamos National Laboratory \\ Los Alamos, NM 87545
}

\section{Introduction/Motivation}

The purpose of this report is to assess the adequacy of current cylinder test results to serve as a baseline for comparison with cylinder tests conducted on stockpile return material. The question of adequacy arises because cylinder tests on stockpile return material will now be a standard part of the suite of tests conducted on stockpile return material as part of the surveillance program. If these tests are to be truly useful, there must be sufficient amounts of data on "unaged" and "undamaged" material. Therefore, the question of whether sufficient amounts of "baseline" data do exist was put to the author by Greg Buntain, who is in charge of stockpile surveillance for HE at LANL.

\section{Background}

\section{A Cylinder Test, Briefly}

Cylinder tests have long been used to calibrate equations of state (EOSs) for high explosives (HEs), primarily the JWL (Jones-Wilkins-Lee) equation of state. A copper cylinder of a given diameter and length is filled with the HE of interest, and then is detonated at one end. A camera (generally streak, sometimes flash) system is used to record the subsequent expansion of the cylinder, and time-of-arrival pins are placed along the length of the cylinder and used to determine the detonation velocity. The results of the experiment are the pin arrival times and the film record.

\section{The Data Collection Process}

Part of the reason that the question posed in the introduction was put to me is that $I$ have been working on collecting data on cylinder test experiments conducted at LANL. There are cylinder test experiments that have been conducted in the recent past by Larry Hill, as well as other earlier tests fired primarily during the early and mid-seventies. The data from Larry's tests are straightforward to collect and include cylinder expansion profiles. 
The problems with finding data from the earlier tests have been myriad. It begins with the question of where to start. By talking to current staff members, one can get an idea of who conducted the older tests. All of the other staff members involved in the tests, it turned out, had retired; at least one (Wayne Campbell) had passed away. By far the best lead was in the direction of Wayne Campbell's notebooks. Wayne kept meticulous track of the experiments that he performed, and by far a majority of the tests that have been located were his. Other experimentalists that were doing cylinder tests then, when questioned, were not able to produce any concrete records of their tests. They pointed to possible cylinder test data files being stored on computers, but those leads produced data from only one experiment, and that explosive was not a commonly-used one. They also pointed to quarterly reports from GMX/M Division (now essentially DX), and those reports have actually produced some information for tests conducted by experimentalists other than Wayne Campbell. There is the additional possibility of poring over all of the shot records for everything that DX/M/GMX did in hopes of finding more cylinder tests. This daunting task that has been partially completed by the author with the significant and appreciated help of John Ramsay, a retiree who worked with explosives while at LANL. This has so far turned up only 2 apparently reasonable test results, both for PBX 9502, which are just being analyzed, after some significant delays due to personnel unavailability and some classification issues with which the author had to deal.

In any case, no cylinder expansion profiles are available from the earlier tests for PBX materials relevant to the stockpile. This means that it is necessary to obtain the film records of the test and re-read them in order to get the expansion profiles. From the shot numbers, the films can be correlated with an archive location and then retrieved. As they are re-read, the preliminary analysis can be completed. This work has just recently been completed.

\section{Current Data Compilation}

Below are tabulated all of the tests for which information has been definitively located, for the two HEs of most interest to the stockpile, PBX 9501 and PBX 9502. These tables include both "modern" shots performed by Larry Hill that have a 15- at the beginning of the shot number, as well as the "classic" earlier tests which have a letter at the beginning of the shot number designation. The letters indicate the firing point at which they were fired $(\mathrm{B}=$ Meenie and $\mathrm{C}=$ Eenie).

The columns in the tables include the following: shot number, date, nominal cylinder size, whether the shot was baseline or not, readability, expansion, and "level of confidence". The shot number is a unique identifier of each shot, and the date is of general interest and helps to further differentiate between "modern" and "classic" test. Nominal cylinder size is included because the cylinder tests have not always been performed on identically sized cylinders, and scaling issues could become a valid concern. Whether the test is baseline or not is critical to determining whether they contribute to the baseline data. All of the earlier shots are assumed to be baseline; none of the material concerning the tests that was acquired by the author indicates that they were performed on aged or damaged material. Because of some of the earlier tests' peculiarities, the columns for readability and expansion are included, as well as the column for level of confidence; the latter metric was determined by Larry Hill and Richard Catanach and indicates how comfortable they are with the quality of data and amount of information for the shot $(\mathrm{L}=$ low, $\mathrm{M}=$ medium, 
and $\mathrm{H}=$ high). All of the "modern" tests have good readability, full expansions, and a high $(\mathrm{H})$ level of confidence. It can be noted that the two tests with incomplete expansions do not have a level of confidence given; these tests did not even receive the preliminary analysis - the incomplete expansions earned them a level of no confidence from Larry and Richard.

Because of the uncertainties mentioned above that exist for some of the "classic" tests (lack of full information, making it necessary to assume some variable values in order to do preliminary analyses), the "modern" tests are weighted more heavily in the determination of whether the number of baseline tests is sufficient. There also needs to be considered the question of whether there is shot to shot repeatability, or whether small differences from shot to shot in temperature or gaps and spaces between $\mathrm{HE}$ pieces and/or between the $\mathrm{HE}$ and the cylinder wall could upset the repeatability.

There are cylinder test films for other materials that were also re-read (PBX 9404, TATB, NM, PBX 9504, and Comp. B), but those results are not presented here because they do not apply to the question of sufficient number of baselines for comparison to stockpile return materials.

Table 1: Cylinder Test Compilation for PBX 9501

\begin{tabular}{||r|r|c|c|c|c|c||}
\hline $\begin{array}{r}\text { Shot } \\
\text { No. }\end{array}$ & $\begin{array}{r}\text { Shot } \\
\text { Date }\end{array}$ & $\begin{array}{r}\text { Cyl. } \\
\text { Size }\end{array}$ & $\begin{array}{c}\text { Baseline/ } \\
\text { NonBase }\end{array}$ & $\begin{array}{c}\text { Film } \\
\text { Readability }\end{array}$ & $\begin{array}{c}\text { Full } \\
\text { Expansion? }\end{array}$ & $\begin{array}{c}\text { Conf. } \\
\text { Level }\end{array}$ \\
\hline $15-2694$ & $9-9-97$ & 1 in & Baseline & Good & Yes & $\mathrm{H}$ \\
\hline $15-2695$ & $9-10-97$ & 1 in & Baseline & Good & Yes & $\mathrm{H}$ \\
\hline $15-2729$ & $9-23-97$ & 1 in & Baseline & Good & Yes & $\mathrm{H}$ \\
\hline $15-2730$ & $9-24-97$ & 1 in & Nonbase(SR) & Good & Yes & $\mathrm{H}$ \\
\hline $15-2731$ & $9-26-97$ & 1 in & Nonbase(SR) & Good & Yes & $\mathrm{H}$ \\
\hline B-7675 & $1-16-72$ & 1 in & Baseline & Good & Yes & $\mathrm{H}$ \\
\hline B-7676 & $1972-73$ & 1 in & Baseline & Good & Yes & $\mathrm{H}$ \\
\hline B-7677 & $1-24-73$ & 1 in & Baseline & Good & Yes & $\mathrm{H}$ \\
\hline B-7681 & $2-26-73$ & 1 in & Baseline & Fair & Yes & $\mathrm{H}$ \\
\hline C-4521 & $7-22-75$ & 1 in & Baseline & Good & Yes & $\mathrm{H}$ \\
\hline C-4525 & $7-23-75$ & 1 in & Baseline & Good & Yes & $\mathrm{H}$ \\
\hline
\end{tabular}

The acronym SR denotes stockpile return. 
Table 2: Cylinder Test Compilation for PBX 9502

\begin{tabular}{||r|r|r|c|c|c|c||}
\hline $\begin{array}{r}\text { Shot } \\
\text { No. }\end{array}$ & $\begin{array}{r}\text { Shot } \\
\text { Date }\end{array}$ & $\begin{array}{r}\text { Cyl. } \\
\text { Size }\end{array}$ & $\begin{array}{c}\text { Baseline/ } \\
\text { NonBase }\end{array}$ & $\begin{array}{c}\text { Film } \\
\text { Readability }\end{array}$ & $\begin{array}{c}\text { Full } \\
\text { Expansion? }\end{array}$ & $\begin{array}{c}\text { Conf. } \\
\text { Level }\end{array}$ \\
\hline $15-2554$ & $10-31-96$ & 1 in & Baseline & Good & Yes & H \\
\hline $15-2555$ & $11-01-96$ & 1 in & Nonbase(A/D) & Good & Yes & H \\
\hline $15-2587$ & $2-04-97$ & 1 in & Nonbase(A/D) & Good & Yes & H \\
\hline $15-2588$ & $2-04-97$ & 1 in & Nonbase(A/D) & Good & Yes & H \\
\hline B-8305 & $6-22-78$ & 1 in & Baseline & Poor & Yes & L \\
\hline B-8367 & $2-5-79$ & 1 in & Baseline & Poor & No & \\
\hline B-8407 & $4-18-79$ & 1 in & Baseline & Good & No & \\
\hline C-4454 & $2-28-75$ & 1 in & Baseline & Good & Yes & H \\
\hline C-4455 & $3-3-75$ & 1 in & Baseline & Good & Yes & H \\
\hline
\end{tabular}

The A/D for the nonbase shots denoted "abused/damaged" 9502.

\section{Recommendations}

In order to make a judgment concerning the adequacy of the data described above as a baseline for comparison with stockpile returns, one needs to consider how many of the shots for each material would be applicable or useful. One aspect of importance to consider is scaling. Not all of the cylinders used in cylinder tests have been the same diameter; variations have ranged from 0.311 to 4 inches in diameter. If two cylinders are not the same size, can we expect their results to be scalable which each other and with any subsequent tests? Fortunately, in looking at the tables for the two explosives, we note that none of the tests that made their way into the tables have anything other than a nominal one inch diameter. Therefore, scaling issues do not actually complicate our consideration of the results. Had there been different size cylinders involved, the author would have tried compare them on a same-scale basis, i.e., adjusting the expansion of one so that it was on the same scale as the others.

We also need to be concerned with shot to shot experimental repeatability. For purposes of this article, this repeatability is measured through the level of confidence, as well as by considering the plots that can be found below for repeatability of the expansion profiles. For both materials, all shots listed in the table are plotted. The newer shots are all represented by solid lines, while the older shots are represented independently of one another by using different line styles and using symbols without lines. This method of presentation was chosen on the assumption that the new shots would likely be very repeatable with each other, while the older shots would be more likely to vary and thus should be more distinguishable from one another. For both materials, there are two plots shown. The top of the two provides a representation of the entire expansion range for the shots, while the lower one shows a more limited expansion range in order to more strongly show any differences in initial (ring-up) behavior.

Profiles of the surface velocity of the cylinder would provide a much better comparison of shots than the expansions since the velocity is more sensitive to various effects (and would thus be more sensitive to shot to shot variations) than the cylinder displacement is, but that information has not been measured in any of the LANL cylinder tests. While there are more precise methods 
of comparing two profiles than just looking at them visually, these plots provide a quick, rough estimate of the effect of shot to shot variations on expansion profiles.

\section{PBX 9501}

Looking at the table for 9501 , one sees that nine of the tests (three "modern", six "classic") could be considered baseline. All of the "modern" baseline shots should be adequate, and if we discount the one "classic" test with only fair readability, we are still left with five "classic" tests. The level of confidence is high on all for the shots for this material, even for the test that had a film with only fair readability. To retain a conservative outlook, we will still discount that fair test.

If we look at the two figures for 9501 , we can see that at least with a coarse visual examination, the tests are quite repeatable, varying from one another by only a fraction of a $m m$ of expansion. Since only 1 solid line is visible, the "modern" shots agree extremely well, even those which were conducted on stockpile return material. This gives us reasonable confidence that shot to shot repeatability should not be a significant problem.

Overall, then, we have eight adequate tests, three "modern" and five "classic". This should be a sufficient minimum for comparison with future stockpile return material. More would always be highly appreci-

\section{Comparison of Expansion Profiles -- PBX 9501}
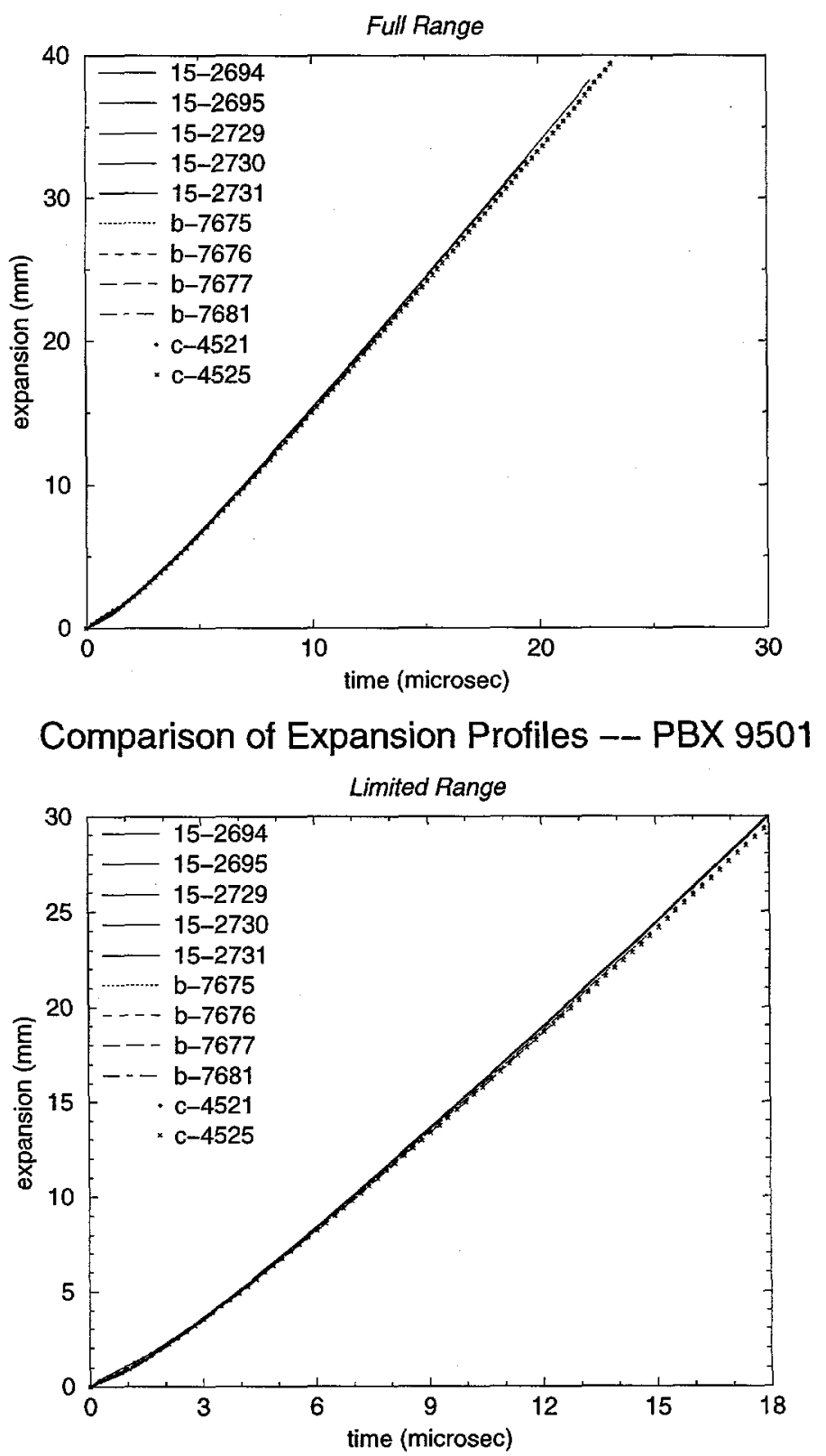
ated, but not at the expense of other time-critical programs. 


\section{PBX 9502}

If we look at the results for 9502 , and discount those which are nonbaseline (three of the "modern"), and those which have either poor readability or do not cover the whole expansion (another three), then we have two good "classic"s and one "modern". All of these remaining shots have been given a high level of confidence.

Looking at the plots for 9502 , we see that except for some small early ring-up differences (which are something that should be explored at some point), the shots agree extremely well except for shot b8305. This shot is the one with poor readability that was already discounted above (the two without full expansions are not plotted), so it is not surprising that that test result might differ from the others, probably due to an indistinct cylinder edge on the test film. We also see again, as we did with 9501 , that the nonbaseline expansions do not differ visually from the baseline samples, but they are still not to be included in the baseline inventory for obvious reasons. It is entirely possible that a more thorough and precise comparison than "eye-balling" plots would turn up some differences.
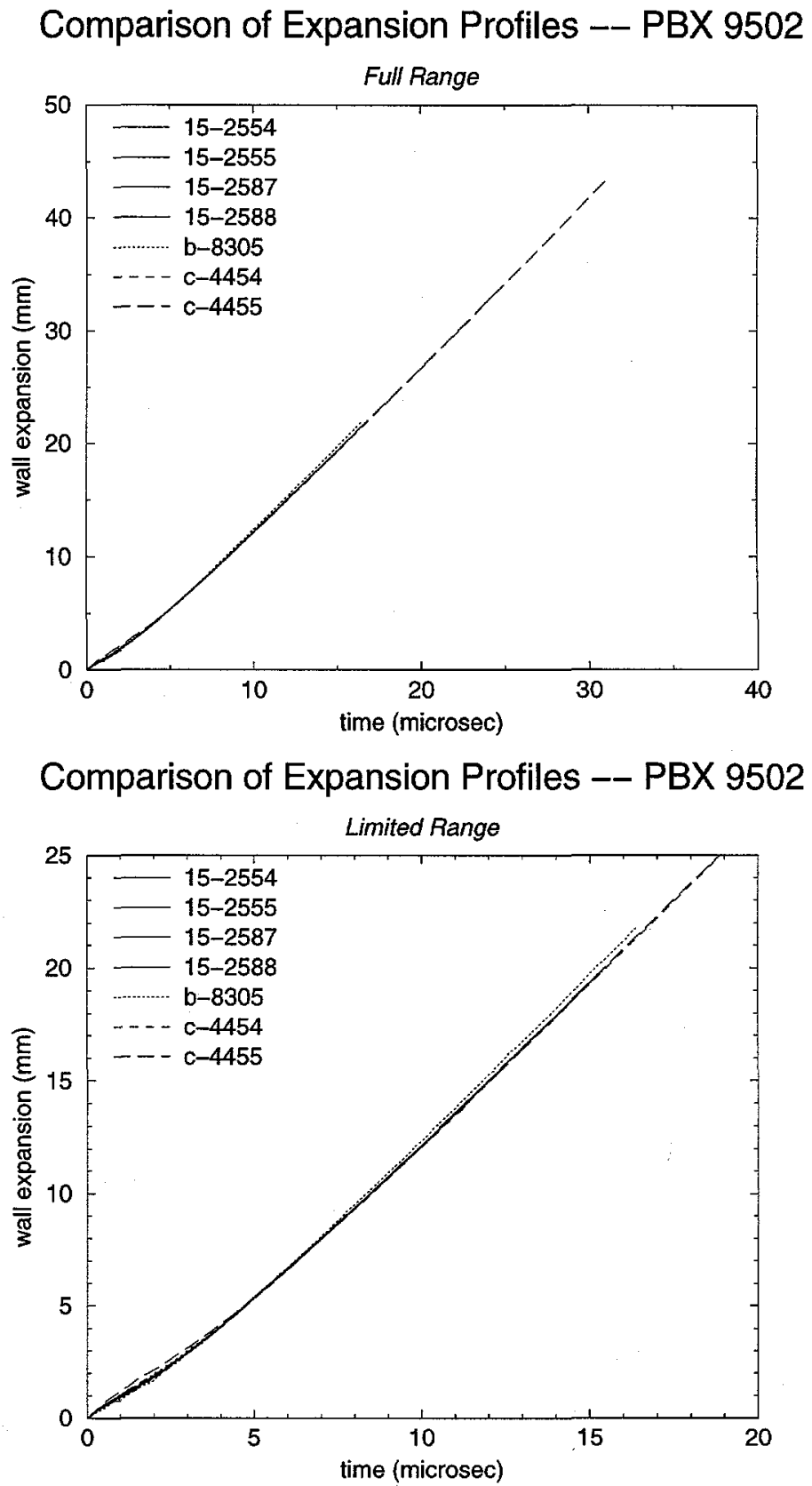

My recommendation is to do a minimum of one more 9502 baseline cylinder test; compared to the number of 9501 baselines (eight), three tests for 9502 is pitiful. However, I think that one more modern test, especially if it compares well with the other one which has already been done, would provide a reasonable minimum. A recent prioritization of needs performed by the primary design and primary weapons physics community determined that there was sufficient baseline data 
for both 9501 and 9502 , but the request here for one more 9502 baseline is rather minor, especially in light of the great disparity in data between 9501 and 9502.

\section{Conclusions}

To summarize, I would suggest that no more 9501 tests are needed, and that there should be one more baseline 9502 cylinder test, for the reasons outlined above. Fulfillment of these minimum requests should provide a sufficient baseline of cylinder test results for comparison with cylinder tests conducted on stockpile return material.

The conclusion above answers the specific question posed in the title of this report. It does not, however, address the more general issue of an appropriate EOS diagnostic test. The cylinder test has limitations, the strongest of which is its geometry. The way that the test is fashioned does not allow for the effects of initial temperature to be measured, and the effects of extreme temperatures are of strong importance to some stockpile systems. Also, gaps (between pieces of HE or between the $\mathrm{HE}$ and a metal) can be a very significant concern for weapons designers, and the cylinder test cannot handle gaps. Ideally, stockpile return material should be tested under varying temperatures and/or gap conditions, but the cylinder test is unable to handle the temperature effects due to thermal expansion effects and is unable to handle gaps, because the pressures cause the cylinder to burst.

Additionally, there are currently at LANL no cylinder tests which include surface velocity measurements, although LLNL routinely conducts tests with this capability. The information that could be gained from surface velocity measurements is of great use and importance to those concerned with HE modeling/physics, mainly to examine the impact of the reaction zone on EOS, since velocity is much more sensitive to reaction zone effects than displacement of the cylinder is. Therefore, it would be very desirable to have these velocity measurements.

Therefore, it is important to also consider the issue of which test is most appropriate to look at these issues. Current possibilities include the old standby cylinder test, as well as the "sandwich test"; in this test, HE is sandwiched between copper or tantalum plates, tamped at the open end, and line-initiated at one end. The resulting expansion of the plates is planned to be characterized by laser interferometry. This type of test is currently being developed by Larry Hill but has not reached the actual testing stage yet (and the author would like to state that when it does reach that stage, the ability to measure surface velocities should be present for it to be a truly useful).

Another suggested alternative is the "Big Plate test" - a very thin metal plate is placed atop a rectangular HE sample, and point detonated. This is a LLNL test that has recently developed and has become a relatively standard, commonplace test for EOS issues for them (and which does include surface velocity measurements). Possible difficulties with this test include the fact that it is not really an EOS test per se; it is actually an integral test that is not as complicated as, say, a hydrotest. Therefore, drawing EOS information out of its results would not be straightforward, and differences in results could not be attributed to any one particular factor.

The author cannot currently say that one or the other test is "the" test for LANL; that should not be determined solely by the author; it is a question that deserves the serious consideration of many people. However, should a test other than the cylinder test become a standard for LANL, then obviously a baseline for that test would have to be established. 
While the issue of what the "best" EOS test is does not specifically help answer the question of whether a sufficient baseline for cylinder tests exists, if the standards of testing change, then so would the relevance or importance of having a sufficient cylinder test baseline. Additionally, the author feels that it is important to point out that the appropriate test is something that needs to be determined. Discussing this and coming to a reasoned conclusion is infinitely preferable to blithely continuing to do what has been done in the past, sometimes precisely and only because it is what has been done in the past. 